\title{
Distribution and antimicrobial activity of lactic acid bacteria associated with lychee fruits
}

\section{LIN-HU NAN ${ }^{1,3}$, YI-SHENG CHEN ${ }^{1,3}, *$, HUI-CHUNG WU ${ }^{1}$, YU-CHING SU ${ }^{1}$, MIN-CHIN LIAO ${ }^{1}$ and FUJITOSHI YANAGIDA ${ }^{2}$}

\footnotetext{
${ }^{1}$ Department of Biotechnology, Ming Chuan University, No. 5, Deming Rd., Guishan Dist., Taoyuan City, Taiwan

${ }^{2}$ The Institute of Enology and Viticulture, University of Yamanashi, 1-13-1 Kitashin, Kofu, Yamanashi 400-0005, Japan
}

\begin{abstract}
Lychee is a popular fruit in China and southeastern Asia. Although it is very popular, the microbiota of lactic acid bacteria (LAB) associated with lychee remains poorly described. Lychee samples from seven different markets located in three cities in Taiwan were collected and a total of $104 \mathrm{LAB}$ were isolated. Through RFLP analyses of 16S rDNA and rpoA genes for grouping and $16 \mathrm{~S}$ rRNA gene sequencing, these isolates were finally divided into 6 groups (A to F). The most common genera of LAB in lychee samples were Weissella and Leuconostoc. Weissella confusa strain E was found to produce a bacteriocin active against Listeria monocytogenes and some other Gram-positive bacteria. Mass spectrometry analysis revealed the bacteriocin mass to be approximately $3426.77 \mathrm{Da}$, which is different to other known Weissella bacteriocins. In addition, strain MB7 included in the genus Leuconostoc was identified as potential novel species or subspecies on the basis of phylogenetic analysis of $16 \mathrm{~S}$ rRNA, rpoA and pheS gene sequences. Thus, this is the first report describing the distribution and varieties of LAB associated with lychee fruits. In addition, one potential novel LAB species or subspecies and one potential novel bacteriocin were also reported in this study.
\end{abstract}

Keywords Lactic acid bacteria, lychee, bacteriocin, Leuconostoc, Weissella.

To cite this article: NAN L-H, CHEN Y-S, WU H-C, SU Y-C, LIAO, M-C YANAGIDA F. Distribution and antimicrobial activity of lactic acid bacteria associated with lychee fruits. Rom Biotechnol Lett. 2020; 25(6): 2079-2085. DOI: 10.25083/rbl/25.6/2079.2085 


\section{Introduction}

Lychee (Litchi chinensis) is a tropical fruit that has been widely cultivated in China and southeastern Asia for hundreds of years. Lychee fruits are harvested from May to August and usually eaten fresh. The lychee fruit is sweet with perfume-like flavor and is therefore popular in Taiwan. Although lychee is very popular, studies on lactic acid bacteria $(\mathrm{LAB})$ distribution in lychee fruits remain scarce.

Diversity of LAB in various fruits, such as banana, ripe mulberries, watermelons and peaches have been previously studied in our laboratories (CHEN \& al [1]; CHEN \& al [2]; CHEN \& al [3]; CHEN \& al [4]). Various LAB species, included in genera Lactobacillus, Weissella, Leuconostoc, Lactococcus and Enterococcus were previously found in these fruits. In the genus Leuconostoc, species of Leuc. mesenteroides and Leuc. pseudomesenteroides were frequently found in these studies (CHEN \& al [1]; CHEN \& al [2]; CHEN \& al [3]; CHEN \& al [4]). When comparing the $16 \mathrm{~S}$ rRNA gene sequences of the type strains of Leuc. mesenteroides ATCC 8293 ${ }^{\mathrm{T}}$ (KC429780) and Leuc. Pseudomesenteroides LMG 11482 ${ }^{\mathrm{T}}$ (HM443958), similarity approximately $99.57 \%$ was observed. It is therefore difficult to classify these two species in the initial step by using 16S rDNA RFLP analysis.

In the previous study of JANG \& al. [5], Leuconostocspecific PCR-RFLP method was developed to rapidly identifying Leuconostoc isolates from food samples. The only difference between species Leuc. mesenteroides and Leuc. pseudomesenteroides was observed at the digested patterns by restriction endonuclease Tsp509I (JANG \& al [5]). Excepting DNA sequencing analysis and methods described by JANG \& al. [5], a different method with similar identifying ability was expected.
In addition, bacteriocins produced by $\mathrm{LAB}$ can be applied to food preservation and are therefore attracting special interest. Besides isolation and identification, screening for bacteriocin-producing LAB strains always was another objective in our previous studies. A total of nine bacteriocins from Weissella have been previously reported which included those from $W$. confusa A3 (2706.68 Da), W. confusa MBF8-1 (3956.57, 2877.26, 2419.94 Da), W. hellenica QU 13 (4925.12, 4968.40 Da), W. hellenica 4-7 (3205.6 Da), W. paramesenteroides DX (4450 Da) and Weissella cibaria 110 (3487.8 Da) (SRIONNUAL \& al [6]; PAPAGIANNI and PAPAMICHAEL [7]; MASUDA \& al [8]; LEONG \& al [9]; GOH and PHILIP [10]; MALIK \& al [11]). On the whole, study on bacteriocin from species W. confusa remains few.

The three aims of this study were 1) to isolate and characterize LAB from lychee fruits; 2) to develop a different identification method for classifying Leuc. mesenteroides and Leuc. pseudomesenteroides; 3) to purify and characterize bacteriocin from lychee isolated strain.

\section{Materials and Methods}

\section{Lychee fruits samples}

A total of 7 lychee fruit samples were collected at seven traditional markets, located in the following three cities: Taoyuan City (S1-S4), Taipei City (S5 and S6) and Hsinchu County (S7) (Table 1). Each sample was collected aseptically in a sterile plastic bag and delivered to the laboratory within $24 \mathrm{~h}$ and immediately analyzed. Multiple lychee fruits collected from the same sampling point were crushed with hard shells and the mixtures were used for isolation.

Table 1. Analyses results and characteristics of isolates

\begin{tabular}{|c|c|c|c|c|c|c|c|c|}
\hline & & 16S rDNA RFLP groups & r1 & r1 & $\mathbf{r} 2$ & r3 & r4 & r5 \\
\hline & & Final group classification & $\mathbf{A}$ & $\mathbf{B}$ & $\mathbf{C}$ & D & $\mathbf{E}$ & $\mathbf{F}$ \\
\hline Sample & Location & 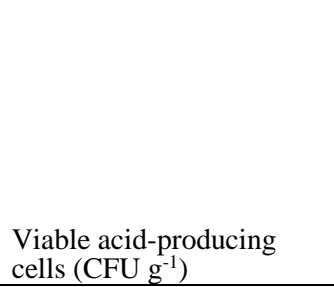 & 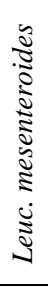 & 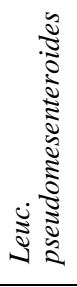 & 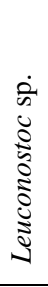 & 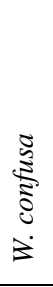 & 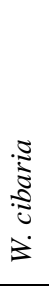 & 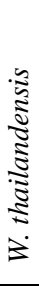 \\
\hline S1 & Taoyuan City & ca. $10^{5}$ & & & & 12 & & \\
\hline $\mathrm{S} 2$ & Taoyuan City & ca. $10^{5}$ & 4 & 4 & & 4 & & \\
\hline S3 & Taoyuan City & ca. $10^{3}$ & & & & 2 & 2 & \\
\hline S4 & Taoyuan City & ca. $10^{5}$ & 2 & 9 & 1 & & & \\
\hline S5 & Taipei City & ca. $10^{7}$ & 17 & 10 & & 1 & & \\
\hline S6 & Taipei City & ca. $10^{5}$ & 3 & 6 & & & 1 & \\
\hline \multirow[t]{2}{*}{ S7 } & Hsinchu County & ca. $10^{7}$ & 10 & 5 & & 2 & 6 & 3 \\
\hline & Total & & 36 & 34 & 1 & 21 & 9 & 3 \\
\hline
\end{tabular}

Abbreviations: Leuc., Leuconostoc; W., Weissella. 


\section{Isolation of $\mathrm{LAB}$}

To isolate $\mathrm{LAB}$, dilutions of the resultant solution $\left(10^{-1}\right.$ to $10^{-6}$ fold) were spread directly onto the surface of Man Rogosa and Sharpe (MRS) (BD, Franklin Lakes, NJ, USA) agar plates and then incubated at $30^{\circ} \mathrm{C}$ for $3-5$ days under anaerobic conditions (Mitsubishi AnaeroPak ${ }^{\mathrm{TM}}$ System, Pack-Anaero; Mitsubishi Gas Chemicals, Tokyo, Japan). To distinguish acid-producing bacteria from other bacteria, $\mathrm{CaCO}_{3}$ with a final concentration of $1 \%$ was added to the MRS agar and the number of viable acidproducing cells were counted (CHEN \& al [4]). Only colonies with a clear zone around them were randomly selected. The randomly selected colonies were streaked on new plates in order to purify the colonies for further characterization. Only Gram-positive, catalase-negative strains were kept and then stored at $-80^{\circ} \mathrm{C}$ in $100 \mathrm{~g} \mathrm{~L}^{-1}$ skim milk broth.

\section{Grouping and identifying of $\mathrm{LAB}$ isolates}

Colony PCR method (SHEU \& al [12]) was used for DNA amplification. PCR reactions were carried out using a Genomics Taq gene amplification PCR kit (Genomics, Taipei, Taiwan) and performed on a T100 Thermal Cycler (Bio-Rad, Hercules, CA, USA). The 16S rDNA RFLP was performed to cluster the LAB isolates into some genotypically related groups for subsequent identification. Three different restriction endonucleases described by Chen \& al. [4], HaeIII (GG/CC), AluI (AG/CT) and MspI (C/CGG), were used to generate the main groups. The isolates were identified to the species level by sequencing the $16 \mathrm{~S}$ rRNA gene as described previously (CHEN \& al [4]). DNA sequencing was performed using an ABI 3730 DNA Analyzer (Applied Biosystems, Foster City, CA, USA). The obtained sequences were subjected to nucleotide-nucleotide BLAST using blastn in the DNA Data Bank of Japan (DDBJ; http://www.ddbj.nig.ac.jp/).

\section{Differentiation of Leuc. mesenteroides and Leuc. pseudomesenteroides}

It is found that the housekeeping gene rpoA similarity between Leuc. mesenteroides (AM711294) and Leuc. pseudomesenteroides (AM711315) is approximately $87.06 \%$ which much lower than that of $16 \mathrm{~S}$ rRNA (99.57\%). An approach from combination of rpoA gene and RFLP was therefore purposed. Amplification of rpoA gene was following the conditions described by NASER \& al. [13]. Potential restriction enzymes were screened by using the simulation option of the Genetyx-Win program ver. 5.1 (Genetyx Co., Japan). Restriction fragments were visualized on a $2 \%$ agarose gel in $1 \times$ TAE.

\section{Screening for bacteriocin-producing strain}

The agar spot test method described by SCHILLINGER and LÜCKE [14] was used to screen the antibacterial activities of isolates. For initial screening, antibacterial activity of colony was detected. W. paramesenteroides BCRC $14006^{\mathrm{T}}$ was used as the indicator strain in this study. Antibacterial activity was further confirmed by $\mathrm{pH}$ adjustment and proteinase $\mathrm{K}$ treatment (SRIONNUAL \& al [6]).

\section{Purification of bacteriocin}

The cell-free supernatant was initially loaded onto a strong cation-exchange column at $8 \mathrm{~mL} / \mathrm{min}$ (TOYOPEARL GigaCap S-650M, Tokyo, Japan). Eluted fractions were collected and tested for activity against W. paramesenteroides BCRC $14006^{\mathrm{T}}$. Secondly, active fractions were collected then loaded onto a hydrophobic interaction column (TOYOPEARL Phenyl-650M, Tokyo, Japan). Eluted fractions with activities were collected then loaded onto a $\mathrm{C}_{18}$ cartridge (Sep-Pak $\mathrm{C}_{18}$, Waters, Milford, MA, USA). The cartridge was initially washed with 5 column volumes of milli $\mathrm{Q}$ water and then eluted by using 20,40, 60 and 100\% acetonitrile/milli Q water (v/v) containing $0.1 \%$ TFA. Bacteriocin activity was determined with the same method described above.

The crude bacteriocin was further purified by reversephase HPLC on a HITACHI machine (5160, 5430; Tokyo, Japan) in a VP 260/10 NUCLEODUR $\mathrm{C}_{18}$ HTec column ( $5 \mu \mathrm{m}$, Macherey-Nagel, Germany), using gradients of (B) acetonitrile in (A) $\mathrm{H}_{2} \mathrm{O}$, both containing $0.1 \%$ TFA. Peptides were initially separated by the following gradient: $10-20 \%$ B over $10 \mathrm{~min}$, then $20-100 \%$ B over 55 min and $100 \% \mathrm{~B}$ over $5 \mathrm{~min}$. Antimicrobial activity of the peptide fractions was tested using the agar-spot test by using the W. paramesenteroides BCRC $14006^{\mathrm{T}}$ as the indicator strain. Fraction showed inhibitory ability was repurified on the HPLC system using the same column. Conditions for the second purification were as follows: $10-51 \%$ B over $10 \mathrm{~min}$, then $51-56 \% \mathrm{~B}$ over $50 \mathrm{~min}$ and $56-100 \%$ B over $5 \mathrm{~min}$. The bacteriocin activity of each observed peak was determined with the same method described above; the corresponding fractions then were stored at $-20^{\circ} \mathrm{C}$ until further study.

\section{Mass spectrometry}

MS analysis was performed on a mass spectrometer (Bruker Microflex, Bruker Daltonics, Bremen, Germany).

\section{Inhibition spectrum of bacteriocin}

The antibacterial activity of purified bacteriocin was tested against several Gram-positive and Gramnegative bacteria listed in Table 2. Duplicate tests were performed and average values were calculated.

\section{Results}

The number of viable acid-producing cells observed in each lychee fruit samples were showed in Table 1. A total of 104 acid-producing bacteria were isolated from the lychee fruit samples. The 104 isolates were temporarily classified into 5 groups ( $\mathrm{r} 1$ to $\mathrm{r} 5$; Fig. 1A) according to cell morphology and the results of the $16 \mathrm{~S}$ rDNA RFLP analysis. In detail, 70 were placed in Group r1, 1 in Group r2, 21 in Group r3, 9 in Group r4 and 3 in Group r5, according to similarities in RFLP patterns after DNA digestion with HaeIII, AluI and MspI.

Representative strains in each group were randomly selected, and 16S rRNA gene sequencing analysis was performed. The results identified Group $\mathrm{r} 1$ isolates as Leuc. mesenteroides or Leuc. pseudomesenteroides, Group r2 as Leuconostoc sp., Group $\mathrm{r} 3$ as Weissella confusa, Group r4 as Weissella cibaria and Group r5 as Weissella thailandensis. 
The simulation results from the Genetyx-Win program ver. 5.1 (Genetyx Co., Japan) showed that AccII (CG/CG) digested fragments of the $r p o A$ PCR product were useful for differentiating Leuc. mesenteroides from Leuc. pseudomesenteroides. Isolates in Group $\mathrm{r} 1$ were further verified based on AccII digested fragments of their rpoA PCR product. A total of 36 strains were identified as Leuc. mesenteroides and re-classified into Group A (Fig. 1B, lane 1; Table 1). The remaining 34 strains were identified as Leuc. pseudomesenteroides and re-classified into Group B (Fig. 1B, lane 2; Table 1). Isolates in Groups $\mathrm{r} 2$ to $\mathrm{r} 5$ were therefore re-classified into Groups $\mathrm{C}$ to $\mathrm{F}$ (Table 1).

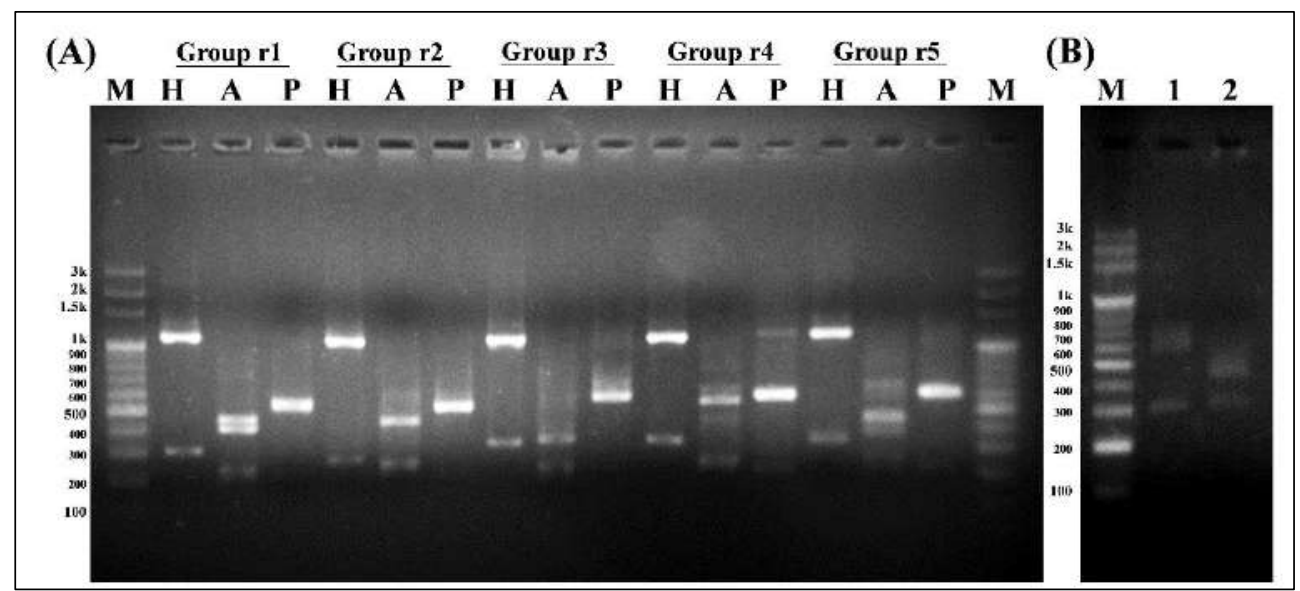

Figure 1. (A) 16S rDNA RFLP patterns of HaeIII, AluI and MspI digests from Groups r1 to r5. Lane M, size marker; H, HaeIII restriction pattern; A, AluI restriction pattern; P, MspI restriction pattern. (B) AccII digested patterns of rроA gene. Lane M, size marker; 1, Leuc. mesenteroides isolate; 2, Leuc. pseudomesenteroides isolate.

Strain MB7 in Group C showed the highest sequence homology, up to $99.25 \%$, with the $16 \mathrm{~S}$ rRNA gene sequences (LC259518), 90.07\% with the rpoA gene sequences (LC259520) and 86.29\% with the pheS gene sequences (LC259519) of Leuconostoc mesenteroides subsp. suionicum DSM 20241 ${ }^{\mathrm{T}}$ (CP015247, AM711330 and AM711232). Based on the results obtained in the current study, strain MB7 was identified as Leuconostoc sp.

Bacteriocin producing ability of all 104 strains were determined and only $W$. confusa strain E showed antibacterial activities against the indicator strain $W$. paramesenteroides BCRC $14006^{\mathrm{T}}$ (Table 2). Bacteriocin from
W. confusa strain E maintained its antibacterial activity after neutralization ( $\mathrm{pH} 6.8)$; however, activity was completely lost after treatment with Proteinase K.

The supernatant from W. confusa strain E was serially purified by cation-exchange and hydrophobic interaction columns. These active fractions obtained from hydrophobic interaction column were desalted by using the $\mathrm{C}_{18}$ cartridges (Sep-Pak $\mathrm{C}_{18}$, Waters, Milford, MA, USA) and then purified using reverse-phase HPLC. One well-separated peak (retention time: approximately $21.28 \mathrm{~min}$ ) with bacteriocin activity was observed in this second reverse-phase chromatography step (Fig. 2).

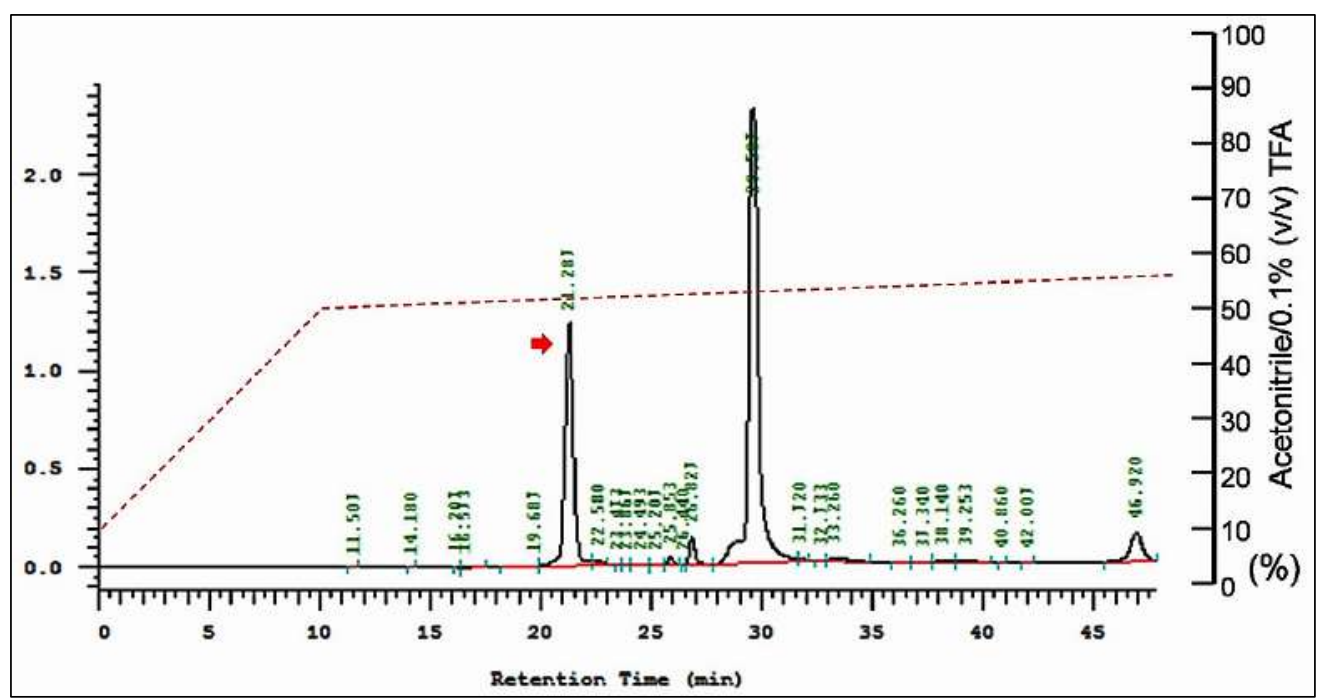

Figure 2. The second purification procedure of $\mathrm{C}_{18}$ reverse-phase chromatography profile of the bacteriocin from $W$. confusa strain E: the peak with bacteriocin activity was observed at 21.28 min, indicated by red arrow at top. The red dotted line indicated the concentration of acetonitrile. 
The purified bacteriocin was also subjected to MALDI-TOF MS analysis in order to accurately determine its molecular mass, which was found to be $3426.77 \mathrm{Da}$ (Fig. 3). The antagonistic effect of purified bacteriocin from $W$. confusa strain $\mathrm{E}$ on different Gram-positive and Gram-negative bacteria was tested (Table 2). The bacteriocin from $W$. confusa strain $\mathrm{E}$ showed inhibitory activity to growth of Lis. monocytogenes BCRC 14845 and some other LAB species as listed in Table 2.

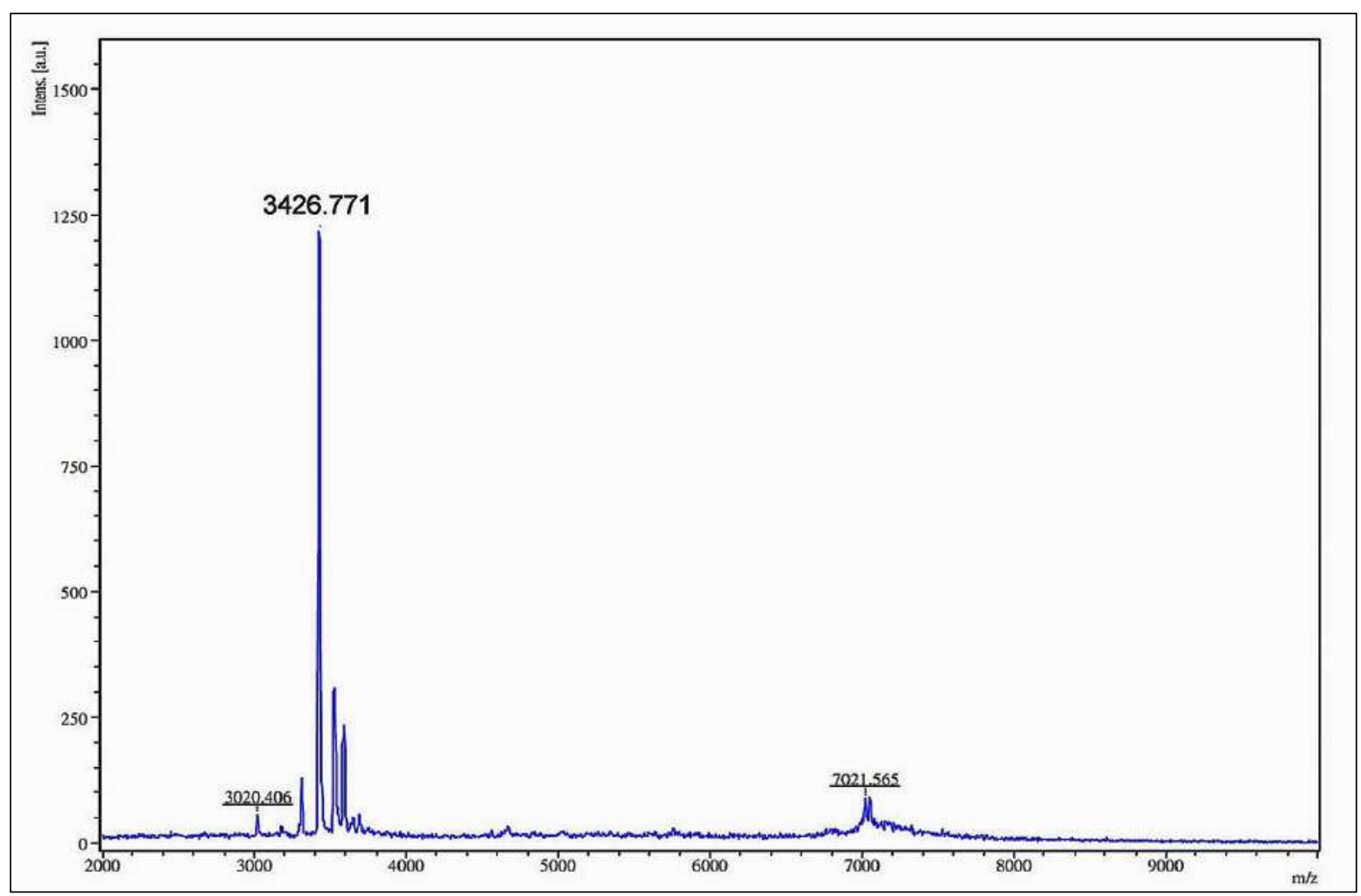

Figure 3. MALDI-TOF mass spectrum analysis of the purified bacteriocins from W. confusa strain E. Bacteriocin yielded a fragment with a mass (m/z) of 3426.77 Da.

Table 2 Inhibitory spectra of bacteriocin from $W$. confusa strain E.

\begin{tabular}{|c|c|c|c|}
\hline Indicator strains & Medium & $\begin{array}{l}\text { Incubation temp. } \\
\qquad\left({ }^{\circ} \mathbf{C}\right)^{\dagger}\end{array}$ & $\underset{\alpha}{\text { Inhibitory ability }}$ \\
\hline Lis. monocytogenes BCRC 14845 & $\mathrm{BHI}$ & 37 & + \\
\hline L. sakei subsp. sakei JCM $1157^{\mathrm{T}}$ & MRS & 30 & - \\
\hline L. crustorum JCM $15951^{\mathrm{T}}$ & MRS & 30 & - \\
\hline L. farciminis BCRC $14043^{\mathrm{T}}$ & MRS & 30 & - \\
\hline L. formosensis $\mathrm{S} 215^{\mathrm{T}}$ & MRS & 30 & - \\
\hline Lc. lactis subsp. lactis BCRC $12312^{\mathrm{T}}$ & MRS & 30 & - \\
\hline Lc. lactis subsp. cremoris BCRC $12586^{\mathrm{T}}$ & MRS & 30 & - \\
\hline Lc. lactis subsp. hordniae BCRC $80474^{\mathrm{T}}$ & MRS & 30 & - \\
\hline Lc. taiwanensis BCRC $80460^{\mathrm{T}}$ & MRS & 30 & - \\
\hline W. paramesenteroides BCRC $14006^{\mathrm{T}}$ & MRS & 30 & + \\
\hline W. viridescens $\mathrm{BCRC} 11650^{\mathrm{T}}$ & MRS & 30 & + \\
\hline Ent. pseudoavium NBRC $100491^{\mathrm{T}}$ & MRS & 30 & + \\
\hline Ent. gilvus NBRC $100696^{\mathrm{T}}$ & MRS & 30 & + \\
\hline Escherichia coli BCRC 11775 & LB & 37 & - \\
\hline Acinetobacter baumannii ATCC $10591^{\mathrm{T}}$ & LB & 37 & - \\
\hline B. thuringiensis BCRC 14616 & LB & 37 & - \\
\hline B. subtilis subsp. subtilis ATCC $6051^{\mathrm{T}}$ & LB & 37 & - \\
\hline
\end{tabular}

Abbreviation: Lis., Listeria; L., Lactobacillus; Lc., Lactococcus; W., Weissella; Ent., Enterococcus; B., Bacillus.

${ }^{\alpha}$ Determined using the agar spot test.

The temperature used to grow the indicator strain during exposure to bacteriocin.

+ , inhibitory zone observed; -, no inhibitory zone observed. 


\section{Discussion}

In the current study, heterofermentive Leuconostoc and Weissella species were the most common genera observed in the 7 analyzed lychee samples. On the whole, Leuc. mesenteroides and Leuc. pseudomesenteroides were the dominant species found in the lychee samples (Table 1). They were found in 5 of 7 lychee samples, excepted lychee samples S1 and S3. Similar results were also observed at the distribution of W. confusa. In contrast to Leuc. mesenteroides, Leuc. pseudomesenteroides and $W$. confusa, the remaining LAB species were less found in these lychee samples. Although samples S1 to S4 were collected in the same city, differences in diversity were observed. On the other hand, samples S2 and S5 were collected in different cities, similar diversity was observed. In addition, LAB species found in this study, such as Leuc. mesenteroides, Leuc. pseudomesenteroides, and W. cibaria, have been also previously found in other Taiwanese fruits (CHEN \& al [1]; CHEN \& al [2]; CHEN \& al [3]; CHEN \& al [4]). Regional similarities and differences in diversity were observed in the current study.

In this study, AccII digested fragments of the rpoA PCR product were used to classify species Leuc. mesenteroides and Leuc. pseudomesenteroides. A total of 70 Leuconostoc isolates were therefore exactly divided to the group which they belonged. To confirm its feasibility, more isolates in Groups A and B were selected and then checked by analyzing their rpoA gene sequences. The obtained results suggested that this method was feasible for classification. Nevertheless, a more efficient identification method for Leuconostoc species with high gene similarities, such as species-specific PCR, was still desired.

In addition, strain MB7 showed low similarities to the type strains in the results of pheS and rpoA gene analysis. The obtained results of genetic analyses suggest the possibility of being a potential novel species or subspecies of Leuconostoc. To clarify this, additional genetic and physiological information, such as GC content, saccharide fermentation ability and DNA relatedness values between strains and the closest type strains, are necessary.

Studies on bacteriocins from $W$. confusa remain scarce. The molecular size of bacteriocin from $W$. confusa strain E (3426.77 Da) was different to those produced by $W$. confusa A3 (2706.68 Da) and W. confusa MBF8-1 (3956.57, 2877.26, 2419.94 Da) (GOH and PHILIP [10]; MALIK \& al [11]). Besides difference in molecular size, bacteriocin from $W$. confusa strain E showed inhibitory ability against Listeria monocytogenes, but bacteriocin from strain W. confusa A3 did not (GOH and PHILIP [10]) (Table 2). A contrasting result was observed at their inhibitory abilities against Escherichia coli $(\mathrm{GOH}$ and 2084
PHILIP [10]) (Table 2). Different characteristics between bacteriocins from $W$. confusa strains E and A3 were observed. Less information about bacterioicns from W. confusa MBF8-1 was available and it is therefore difficult to make comparison in the current study. No corresponding molecular size to other Weissella bacteriocins was found, this possibly indicating the presence of a novel bacteriocin. To confirm this, the amino acid sequence must be subjected to purification and identification analysis in the future.

In conclusion, this is the first report describing the distribution and varieties of LAB that associated with lychee fruits. A useful classification method for differentiating Leuc. mesenteroides from Leuc. pseudomesenteroides was purposed. One potential novel species or subspecies of Leuconostoc was found in the current study. One potential novel bacteriocin from $W$. confusa was also found in this study. The detailed characteristics of bacteriocin, including amino acid sequences, heat stability, and their sensitivity to enzymes, were not established in the current study. Future studies in our laboratory will characterize and identify the bacteriocin, and we anticipate it will be useful as food preservative.

\section{Conflict of Interest}

No conflict of interest declared.

The first two authors contributed equally to this work.

\section{References}

1. Y.S. CHEN, H.C. WU, F. YANAGIDA. Isolation and characteristics of lactic acid bacteria isolated from ripe mulberries in Taiwan. Braz. J. Microbiol. 41, 916-921 (2010).

2. Y.S. CHEN, H.C. WU, S.F. PAN, B.G. LIN, Y.H. LIN, W.C. TUNG, Y.L. LI, C.M. CHIANG, F. YANAGIDA. Isolation and characterization of lactic acid bacteria from yan-taozih (pickled peaches) in Taiwan. Ann. Microbiol. 63, 607-614 (2013).

3. Y.S. CHEN, H.C. WU, C.R. YU, Z.Y. CHEN, Y.C. LU, F. YANAGIDA. Isolation and characterization of lactic acid bacteria from xi-gua-mian (fermented watermelon), a traditional fermented food in Taiwan. Ital. J. Food Sci. 28, 9-14 (2016).

4. Y.S. CHEN, Y.J. LIAO, Y.S. LAN, H.C. WU, F. YANAGIDA. Diversity of Lactic Acid Bacteria Associated with Banana Fruits in Taiwan. Curr. Microbiol. 74, 484-490 (2017).

5. J. JANG. B. KIM, J. LEE, H. HAN. A rapid method for identification of typical Leuconostoc species by 16S rDNA PCR-RFLP analysis. J. Microbiol. Methods 55, 295-302 (2003). 
6. S. SRIONNUAL, F. YANAGIDA, L.H. LIN, K.N. HSIAO, Y.S. CHEN. Weissellicin 110, a newly discovered bacteriocin from Weissella cibaria 110, isolated from plaa-som, a fermented fish product from Thailand. Appl. Environ. Microbiol. 73, 22472250 (2007).

7. M. PAPAGIANNI and E.M. PAPAMICHAEL. Purification, amino acid sequence and characterization of the class IIa bacteriocin weissellin A, produced by Weissella paramesenteroides DX. Bioresour. Technol. 102, 6730-6734 (2011).

8. Y. MASUDA, T. ZENDO, N. SAWA, R.H. PEREZ, J. NAKAYAMA, K. SONOMOTO. Characterization and identification of weissellicin $\mathrm{Y}$ and weissellicin $\mathrm{M}$, novel bacteriocins produced by Weissella hellenica QU 13. J. Appl. Microbiol. 112, 99-108 (2012).

9. K.H. LEONG, Y.S. CHEN, Y.H. LIN, S.F. PAN, B. YU, H.C. WU, F. YANAGIDA. Weissellicin L, a novel bacteriocin from sian-sianzih-isolated Weissella hellenica 4-7. J. Appl. Microbiol. 115, 70-76 (2013).
10. H.F. GOH AND K. PHILIP. Purification and characterization of bacteriocin produced by Weissella confusa A3 of dairy origin. PLoS One 10, e0140434 (2015).

11. A. MALIK, S. SUMAYYAH, C.W. YEH, N.C. HENG. Identification and sequence analysis of pWcMBF8-1, a bacteriocin-encoding plasmid from the lactic acid bacterium Weissella confusa. FEMS Microbiol. Lett. 363, pii: fnw059 (2016).

12. D.S. SHEU, Y.T. WANG, C.Y. LEE. Rapid detection of polyhydroxyalkanoate-accumulating bacteria isolated from the environment by colony PCR. Microbiology 146, 2019-2025 (2000).

13. S.M. NASER, F.L. THOMPSON, B. HOSTE, D. GEVERS, P. DAWYNDT, M. VANCANNEYT, J. SWINGS. Application of multilocus sequence analysis (MLSA) for rapid identification of Enterococcus species based on rpoA and pheS genes. Microbiology 151, 2141-2150 (2005).

14. U. SCHILLINGER and F.K. LÜCKE. Antibacterial activity of Lactobacillus sake isolated from meat. Appl. Environ. Microbiol. 55, 1901-1906 (1989). 